\title{
Dosing practice of low molecular weight heparins and its efficacy and safety in cardiovascular inpatients: a retrospective study in a Chinese teaching hospital
}

Huimin X ${ }^{1}$, Hongwen $\mathrm{Cai}^{2}$, Zhongshu Qian ${ }^{1}$, Geng X $\mathrm{u}^{3}$, Xiaofeng Yan ${ }^{1}$ and Haibin Dai ${ }^{1 *}$

\begin{abstract}
Background: Low-molecular-weight heparins (LMWHs) are safe and effective anticoagulant options for cardiovascular patients when applied as body weight-adjusted doses. However, there are some barriers that make it difficult to implement weight-adjusted doses in clinical practice. Therefore, it is vital to learn the dosing practices of LMWH and its efficacy and safety in clinical practice.
\end{abstract}

Methods: A retrospective study was conducted in cardiovascular inpatients who had received at least one dose of LMWH during a 6-month period. Appropriateness of LMWH dosing was determined and major clinical outcomes (major adverse vascular events and major bleeding) during hospitalization were evaluated.

Results: A total of 376 admissions representing 364 patients received LMWH treatment. Of these, 17.0\% (64/376) of admissions did not have body weight records. Of the 312 admissions included for the outcome study, only 34 cases (10.9\%) received the recommended doses of LMWH, while 51 cases (16.3\%) received mild underdoses, 223 cases $(71.5 \%)$ received major underdoses and $4(1.3 \%)$ received excess doses. There were 10 major adverse vascular events, which occurred more often in patients receiving excess doses of LMWH than in patients receiving recommended, mild or major underdoses $(50 \%, 2.9 \%, 2.0 \%$ and $2.7 \%$, respectively, $P<0.001)$. After multivariable analysis, severe renal insufficiency was an independent risk factor for major adverse vascular events [odds ratio (OR), 31.93; 95\% confidence interval (Cl), 5.99-170.30; $P<0.001]$. No major bleeding was recorded.

Conclusions: Underdose of $\mathrm{LMWH}$ is commonly used in cardiovascular inpatients, which was suboptimal according to guidelines. Using LMWH at a fixed, low dose for treatment purposes in patients without severe renal insufficiency was not associated with a higher risk of adverse vascular events in the current study, though larger studies with extended follow-ups are required to fully assess the long-term consequences of LMWH underdosing.

Keywords: Low molecular weight heparin, Dosing practice, Cardiovascular inpatients, Efficacy, Safety

\section{Background}

Cardiovascular diseases are the leading cause of morbidity and mortality in the world. Thrombosis is the final biological evolution of the atherosclerotic process, which promotes the development and progression of cardiovascular diseases [1]. In recent years several clinical trials have established, that low molecular weight heparins

\footnotetext{
* Correspondence: haibindai@zju.edu.cn

${ }^{1}$ Department of Pharmacy, Second Affiliated Hospital, Zhejiang University

School of Medicine, Hangzhou 310009, China

Full list of author information is available at the end of the article
}

(LMWHs) are safe and effective anticoagulant options for patients with venous thromboembolism (VTE), acute coronary syndrome (ACS), pulmonary embolism, unstable angina and non-ST-segment elevation myocardial infarction [2-5]. This is partly due to the fact that LMWHs have superior pharmacokinetic properties as compared to unfractionated heparin (UFH) and without the need for routine coagulation tests [6]. Therefore, LMWHs have replaced UFH in most situations [7]. However, LMWHs have a longer half-life than UFH, with no potential for full reversal. Thus, if an excess dose of

\section{Biomed Central}


LMWH is given, it may result in equal or more devastating outcome than UFH. LMWHs are typically administered for embolism therapy, based on body weight, creatinine clearance and age ( $\geq 75$ years) [6]. Appropriate dosing of LMWH is vital for its efficacy and safety. Previous data have shown a relationship between LMWH dose, the intensity of anticoagulation and incidence of major hemorrhage, including intracranial bleeding [8].

However, there are some barriers existing in "real world" clinical practice that make adherence to weightadjusted doses, according to the dose-finding trials difficult [9-11]. First, accurate weight assessment is a challenge for seriously ill patients. Second, due to the high concentration of pre-filled doses of LMWH, precise measurement of a weight-based dose is difficult; this could lead to an increase in medical errors and drug waste [12]. Third, patients in real-world cardiovascular units tend to be older, have more comorbidity and are taking more prescribed drugs compared with those in clinical trials [13]. Therefore, in China, some cardiologists tend to use a lower, fixed dose of LMWH relative to the dose suggested by Chinese guidelines and recommended from the clinical trials, to reduce the perceived risk of hemorrhage and to simplify the dosing regimen. However, to our knowledge, the efficacy and safety of this "real word" clinical practice has not yet been studied.

In this retrospective study from a Chinese teaching hospital, we examined the dosing practice of LMWHs, and then determined the efficacy and safety of this practice in cardiovascular inpatients discharged from Jan 1 to Jun 30, 2010.

\section{Methods}

\section{Study subjects}

This study was conducted in a general, universityaffiliated, teaching hospital with 2,200 licensed inpatient beds, and approximately 77,000 admissions per year. Using an electronic medical records database, the patients that were $>18$ years of age and who were discharged from cardiovascular wards between Jan 1 to Jun 30, 2010 were selected. Multiple admissions of a single patient were counted as separate events. An admission was excluded if the patient did not receive any LMWH agents, received a single dose of LMWH, or had no weight record (Figure 1). The study protocol was approved by the medical ethics committee of the Second Affiliated Hospital, Zhejiang University School of Medicine, China (No. 2012-37).

Three types of LMWHs were used in this hospital: Clexane $^{\circledR}$ (Enoxaparin Sodium Injection, Aventis Intercontinental, $0.4 \mathrm{ml}$ : 4000AxaIU), Fraxiparine ${ }^{\circledR}$ (Nadroparin Calcium Injection, GlaxoSmithKline Inc, $0.4 \mathrm{ml}$ : 4100AxaIU), and Fragmin ${ }^{\circledR}$ (Dalteparin Sodium Injection,

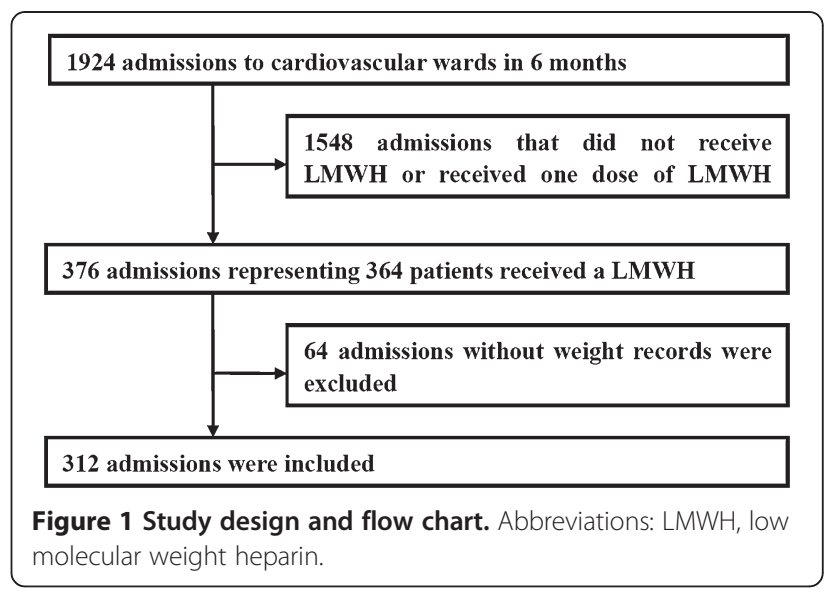

Pfizer Inc, 0.2ml: 5000AxaIU) (Table 1). All LMWHs were administered by nurses during the hospitalization.

\section{Data collection and definition}

A chart review was conducted for each patient included in the study. Data included basic patient demographics (gender, age, weight, and height), clinical parameters (blood creatinine, diagnosis and treatment), dosage of LMWH, and clinical outcomes (major adverse vascular events and major bleeding) during the hospitalization. The body-mass index (BMI) was calculated by dividing the individual's weight (in $\mathrm{kg}$ ) by the square of his or her height (in meters). Hypertension was determined by blood pressure $>140 / 90 \mathrm{mmHg}$ or current use of antihypertensive medication. Severe renal insufficiency (RI) was determined by creatinine clearance $<30 \mathrm{ml} / \mathrm{min}$. Creatinine clearance was estimated by the Cockcroft-Gault equation [140 - age (years)] $\times$ weight $(\mathrm{kg}) \times(0.85$ if female) / $[72 \times$ serum creatinine $(\mathrm{mg} / \mathrm{dl})]$. Medication orders were evaluated with the initial dose prescribed. Dosing errors were determined strictly on the initial $\mathrm{mg} / \mathrm{kg} / \mathrm{dose}$. Interval frequency for LMWH was also collected, which was adjusted by creatinine clearance. The recommended LMWH dosage was defined in accordance with product package inserts (Table 1). Because clinical evidence of dosing strategies for nadroparin and dalteparin in patients with RI and elderly patients $(\geq 75$ years) are limited, we used the dosing strategies recommended from the data on the use of enoxaparin [14].

\section{Table 1 Three types of low-molecular-weight heparins} used

\begin{tabular}{|c|c|c|}
\hline Drug & Recommended usage & Individual adjustment \\
\hline Enoxaparin & $\begin{array}{l}100 \mathrm{IU} / \mathrm{kg} \\
\text { every } 12 \mathrm{~h}\end{array}$ & $\begin{array}{l}\text { 1. } 75 \% \text { of the recommended } \\
\text { dose, every }\end{array}$ \\
\hline Nadroparin & $\begin{array}{l}86 \mathrm{IU} / \mathrm{kg} \\
\text { every } 12 \mathrm{~h}\end{array}$ & $\begin{array}{l}12 \text { hours (age } \geq 75 \text { years); } \\
\text { 2. } 50 \% \text { of the } \\
\text { recommended dose, every }\end{array}$ \\
\hline Dalteparin & $\begin{array}{l}120 \mathrm{IU} / \mathrm{kg} \\
\text { every } 12 \mathrm{~h}\end{array}$ & $\begin{array}{l}24 \text { hours (creatinine } \\
\text { clearance }<30 \mathrm{ml} / \mathrm{min} \text { ). }\end{array}$ \\
\hline
\end{tabular}


The following dosing categories were defined: underdose, recommended dose, and excess dose. An underdose or excess dose was defined as $\leq 90 \%$ or $\geq 110 \%$ of the recommended dose (in $\mathrm{mg} / \mathrm{kg} /$ day), respectively. The underdose was further divided into mild underdose $(\leq 90 \%$ but $>80 \%$ of the recommended dose, in $\mathrm{mg} / \mathrm{kg} /$ day) and major underdose $(\leq 80 \%$ of the recommended dose, in $\mathrm{mg} / \mathrm{kg} /$ day).

The efficacy and safety of clinical outcomes were evaluated by major adverse vascular events and major bleeding, respectively. Major adverse vascular events were defined as any of the following complications during in-hospital: death, myocardial re-infarction, recurrent angina, revascularization procedures, ischemic stroke, peripheral or visceral embolism, recurrent deep vein thrombosis or pulmonary embolism. Major bleeding was defined as any intracranial hemorrhage, transfusion of at least 2 units of packed red blood cells, or absolute drop in hematocrit of at least 12\%; these parameters were similar to definitions used in other trials and registries [15].

\section{Statistical analyses}

Continuous variables are reported as mean $\pm \mathrm{SD}$, and categorical variables are reported as numbers (percentage). Significance was determined using $X^{2}$ tests for categorical variables and Student's t-tests or one way analysis of variance (ANOVA) for continuous data variables.

Independent predictors of major adverse vascular events were identified by use of univariable and multivariable logistic regression analysis. Important baseline characteristics such as age, gender, weight, creatinine clearance, hypertension, diabetes mellitus and dosage subgroup of $\mathrm{LMWH}$ were entered into the model. The odds ratio (OR) and corresponding 95\% confidence interval (CI) were reported for each variable in the model. Variables were retained in the final multivariable model if their level of significance was $\leq 0.05$.

\section{Results}

\section{Patient characteristics}

A total of $19.5 \%(376 / 1,924)$ of admissions representing 364 patients in the cardiovascular units received LMWH during this period. Of these, $17.0 \%$ (64/376) were lacking body weight records. Thus 312 admissions were analyzed for outcome analysis. Of these, $4.8 \%$ (15/312) were treated with dalteparin, $24.4 \%(76 / 312)$ were treated with enoxaparin, and $70.8 \%(221 / 312)$ were treated with nadroparin. As shown in Table 2, the mean age of patients was $64 \pm 11$ years, (75.3\% were men). More than half of the patients $(58.6 \%)$ received LMWHs for the treatment of unstable angina and non ST-segment elevation myocardial infarction. Of the 67 atrial fibrillation patients, 7 (10.4\%) had valvular heart disease (mitral
Table 2 Patient and treatment characteristics

\begin{tabular}{ll}
\hline Patient characteristics & \multicolumn{1}{c}{ Data } \\
\hline Age, $y$ & $63.8 \pm 11.4$ \\
$\quad \geq 75$ years, $\mathrm{n}(\%)$ & $65(20.8)$ \\
Female, $\mathrm{n}(\%)$ & $77(24.7)$ \\
Body mass index & $23.8 \pm 3.2$ \\
Weight, $\mathrm{kg}$ & $66.8 \pm 10.9$ \\
Diagnosis, $\mathrm{n}(\%)$ & \\
$\quad$ ST-segment elevation & \\
myocardial infarction & $53(17.0)$ \\
Unstable angina/Non ST-segment & $183(58.6)$ \\
elevation Myocardial infarction & \\
$\quad$ Atrial fibrillation & $67(21.5)$ \\
$\quad$ Deep vein thrombosis & $9(2.9)$ \\
Concurrent medical conditions, $\mathrm{n}(\%)$ & \\
$\quad$ Hypertension & $194(62.2)$ \\
$\quad$ Diabetes mellitus & $69(22.1)$ \\
Severe renal insufficient, $\mathrm{n}$ (\%) & $7(2.2)$ \\
Creatinine clearance, ml/min & $83.1 \pm 27.8$ \\
Treatment variables, $\mathrm{n}(\%)$ & \\
Cardiac catheterization & \\
Percutaneous coronary intervention & $26(8.3)$ \\
Radiofrequency catheter ablation & $195(62.5)$ \\
Length of hospital stay, d & $44(14.1)$ \\
\hline
\end{tabular}

stenosis or prosthetic heart valves) and had used warfarin prior to hospitalization. Of the other 60 atrial fibrillation patients, only 2 had used warfarin prior to hospitalization although there were 30 cases identified as at "high risk" of stroke (defined as CHA2DS2-VASc score $\geq 2$ ) [16]. Seven patients $(2.2 \%)$ with stage 4 chronic kidney disease (CKD) received LMWH treatment.

\section{LMWH dosing practices}

As shown in Table 3, only 34 cases (10.9\%) received the recommended dose of LMWH, 51 cases (16.3\%) received mild underdoses, 223 cases $(71.5 \%)$ received major underdoses, and 4 cases $(1.3 \%)$ received excess doses. There were no statistically significant differences in gender, diagnosis or comorbid diseases, such as hypertension and diabetes mellitus among these groups. Patients receiving excess doses of LMWH were older, weighed more, had a poorer renal function, longer administration duration and hospital stays than the patients receiving the recommended dose $(P<0.05)$. Patients receiving major underdoses of LMWH were younger and weighted more than the patients receiving the recommended doses $(P<0.05)$. None of the patients in underdoses groups had severe RI. Major adverse vascular events occurred more often in patients receiving excess doses of LMWH than in patients receiving recommended, mild or major 
Table 3 Baseline patient characteristics for different dosages of LMWH

\begin{tabular}{|c|c|c|c|c|c|}
\hline Variable & $\begin{array}{c}\text { Major underdose } \\
(\mathrm{n}=223)\end{array}$ & $\begin{array}{l}\text { Mild underdose } \\
\quad(n=51)\end{array}$ & $\begin{array}{c}\text { Recommended } \\
\text { dose }(n=34)\end{array}$ & $\begin{array}{c}\text { Excess dose } \\
(n=4)\end{array}$ & $P$ Value \\
\hline Age, y & $62.1 \pm 10.7$ & $67.0 \pm 11.3$ & $68.6 \pm 12.8$ & $77.0 \pm 17.5$ & $<0.001$ \\
\hline$\geq 75$ years, $\mathrm{n}(\%)$ & $24(10.8)$ & 19 (37.3) & 19 (55.9) & $3(75)$ & $<0.001$ \\
\hline Female, n (\%) & $60(26.9)$ & 10 (19.6) & $6(17.6)$ & $1(25)$ & 0.531 \\
\hline Weight (kg) & $70.3 \pm 9.2$ & $58.2 \pm 9.1$ & $55.8 \pm 8.8$ & $71.5 \pm 9.1$ & $<0.001$ \\
\hline BMl & $24.7 \pm 2.9$ & $21.6 \pm 2.6$ & $21.0 \pm 3.1$ & $26.2 \pm 3.1$ & $<0.001$ \\
\hline Diagnosis, n (\%) & & & & & 0.167 \\
\hline STEMI & 37 (16.6) & $9(17.6)$ & $6(17.6)$ & $1(25)$ & \\
\hline UA/NSTEMI & $126(56.5)$ & $34(66.7)$ & $21(61.8)$ & $2(50)$ & \\
\hline Atrial fibrillation & $54(24.2)$ & $6(11.8)$ & $7(20.6)$ & 0 & \\
\hline DVT & $6(2.7)$ & $2(3.9)$ & 0 & $1(25)$ & \\
\hline Hypertension & $134(60.1)$ & $34(66.7)$ & $23(67.6)$ & $3(75)$ & 0.668 \\
\hline Diabetes mellitus & $53(23.8)$ & $7(13.7)$ & $9(26.5)$ & 0 & 0.267 \\
\hline Severe RI & 0 & 0 & $3(8.8)$ & $4(100)$ & $<0.001$ \\
\hline Creatinine, mg/dl & $0.8 \pm 0.2$ & $0.8 \pm 0.2$ & $1.0 \pm 0.3$ & $2.5 \pm 1.0$ & $<0.001$ \\
\hline Creatinine clearance, $\mathrm{ml} / \mathrm{min}$ & $90.6 \pm 26.8$ & $69.7 \pm 16.4$ & $61.3 \pm 22.6$ & $24.9 \pm 5.0$ & $<0.001$ \\
\hline Administration duration, $d$ & $4.1 \pm 2.1$ & $3.9 \pm 1.8$ & $4.0 \pm 1.6$ & $6.5 \pm 5.6$ & 0.128 \\
\hline Length of hospital stay, $d$ & $8.8 \pm 5.7$ & $9.4 \pm 5.8$ & $8.2 \pm 4.6$ & $14.8 \pm 16.8$ & 0.179 \\
\hline Major adverse vascular events, n (\%) & $6(2.7)$ & $1(2.0)$ & $1(2.9)$ & $2(50)$ & $<0.001$ \\
\hline
\end{tabular}

Abbreviations: LMWH, Low molecular weight heparin; BMI, body mass index; STEMI, ST-segment elevation myocardial infarction; UA/NSTEMI, Unstable angina/Non ST-segment elevation myocardial infarction; DVT, Deep vein thrombosis; RI, renal insufficient.

underdoses $(50 \%, 2.9 \%, 2.0 \%$ and $2.7 \%$, respectively, $P<0.001)$. No major bleeding was recorded in the whole study population.

\section{Major adverse vascular events and risk factors}

There were 10 major adverse vascular events $(3.2 \%)$ in this study, including four deaths, three myocardial reinfarctions, two revascularization procedures and one ischemic stroke. Major adverse vascular events occurred at $5.9 \pm 9.0$ days after admission. There was no difference in the major adverse vascular event rate when comparing different diagnoses $(\mathrm{P}>0.05)$. Major adverse vascular events occurred in 4 patients with ST-segment elevation myocardial infarction (7.5\%), 4 patients with unstable angina/non ST-segment elevation myocardial infarction (2.2\%), 1 patient with atrial fibrillation (1.5\%), and 1 patient with deep vein thrombosis (11.1\%). Univariate analysis of the risk factors of major adverse vascular events is presented in Table 4. Multivariable analysis found that only one risk factor (severe RI) was independently associated with an increased risk for major adverse vascular events (OR, 31.93; 95\% CI, 5.99170.30; $P<0.001$ ), while age $\geq 75$ years, excess doses of LMWH were not independent predictors of major adverse vascular events.

\section{Discussion}

In the present study we assessed LMWH dosing practices in 364 cardiovascular inpatients (376 admissions) and identified the efficacy and safety of LMWH treatment in 312 cases as measured by major adverse vascular events and major bleeding. There is a considerable disparity in LMWH use when comparing clinical practice to the guideline [6]. Seventeen percent of patients (64/376) without body weight records received LMWH, $10.9 \%(34 / 312)$ of patients received the recommended doses of LMWH and $87.8 \%$ (274/312) received underdoses of LMWH. Interestingly, we found that receiving underdoses of LMWH was not a risk factor for major adverse vascular events. The only risk factor for major adverse vascular events was severe RI.

LMWHs are prescribed based on the patient's weight according to dose-finding studies. However, accurate weight assessment is a challenge for seriously ill patients that are due to the limitations of resources, physical space and time [17]. In our study, we found that approximately 1 in 6 patients received LMWHs without having a record of weight. This is similar to a previous study reported that approximately 1 in 10 patients received enoxaparin for treatment of an ACS without weight documentation [13]. Furthermore, it has been reported that estimation of patients' weights by health 
Table 4 Risk factors for major adverse vascular events (univariable analysis)

\begin{tabular}{|c|c|c|c|c|}
\hline \multirow[t]{2}{*}{ Characteristics } & \multicolumn{2}{|c|}{ N (\%) } & \multirow[t]{2}{*}{ OR $(95 \% \mathrm{Cl}) *$} & \multirow[t]{2}{*}{$P$ Value } \\
\hline & $\begin{array}{l}\text { Without major } \\
\text { adverse vascular } \\
\text { events }(n=302)\end{array}$ & $\begin{array}{l}\text { Major adverse } \\
\text { vascular events } \\
(n=10)\end{array}$ & & \\
\hline Age, $\geq 75$ y & $60(20)$ & $5(50)$ & $4.03(1.13-14.38)$ & 0.036 \\
\hline Female & $72(24)$ & $5(50)$ & $3.19(0.90-11.35)$ & 0.071 \\
\hline Weight, >60 kg & $235(78)$ & $10(100)$ & - & 0.086 \\
\hline STEMI & $49(16)$ & $4(40)$ & $3.44(0.94-12.65)$ & 0.071 \\
\hline Hypertension & $186(62)$ & $8(80)$ & $2.50(0.52-11.95)$ & 0.201 \\
\hline Diabetes mellitus & $69(23)$ & 0 & - & 0.079 \\
\hline Severe RI & $4(1.3)$ & $3(30)$ & $31.93(5.99-170.30)$ & 0.001 \\
\hline Inappropriate dose & $269(89)$ & $9(90)$ & $1.104(0.14-8.99)$ & 0.701 \\
\hline Excess dose & $2(0.7)$ & $2(20)$ & $37.5(4.68-300.75)$ & 0.005 \\
\hline Underdose & $267(88)$ & $7(70)$ & $0.306(0.08-1.24)$ & 0.109 \\
\hline Major underdose & $217(72)$ & $6(60)$ & $0.588(0.162-2.134)$ & 0.310 \\
\hline
\end{tabular}

Abbreviations: STEMI, ST-segment elevation myocardial infarction; $R I$, renal insufficient; $O R$, odds ratio; $C l$, confidence interval.

*Reference groups include age $<75$ years, male, weight $\leq 60 \mathrm{~kg}$, no STEMI, no hypertension, no diabetes mellitus, no severe Rl, recommended dose, no excess dose, no underdose, no major underdose.

care providers is inaccurate having a mean error of 9 to $10 \mathrm{~kg}$ [18]. Inappropriate dosing of LMWH can easily occur if the weight is estimated incorrectly, which can lead to medication errors in clinical practice. However, studies of the consequences of inappropriate dosing of LMWHs in real world practices are still scarce.

The major complication of anticoagulant and thrombolytic therapy is bleeding. A previous study demonstrated that patients with ACS often received excess doses of LMWH that was accompanied by an increased risk of major bleeding [15]. In order to decrease the risk of bleeding, some clinicians in China often prefer to choose empirical dose strategies when administering LMWHs instead of those reported in the results of clinical trials or suggested by Chinese guidelines. In our hospital, the most commonly adopted dosing strategies are enoxaparin 4,000AxaIU, nadroparin 4,100AxaIU or dalteparin 5,000AxaIU given twice daily when a patient's weight is $<80 \mathrm{~kg}$. For patients that weigh $\geq 80 \mathrm{~kg}$, enoxaparin 6,000AxaIU, nadroparin 6,200AxaIU or dalteparin 7,500 AxaIU are given twice daily. These dosing strategies reflected the reason for the high rate of $\mathrm{LMWH}$ underdosing in the current study. As a result, there were no major bleeding events in our study; conversely, the rate of major bleeding events has been found to be approximately $1-6.5 \%$ in clinical trials of LMWHs [9-11]. Therefore, the practice of underdosing LMWH done in our hospital appears to be safe.

Unlike excess dosing of LMWH, which is related to a risk of bleeding, foremost concern associated with underdose of LMWH is the risk of embolism. Thus, we determined the efficacy of the current dosing practice of LMWHs, as measured by the incidence of embolism.
Surprisingly, in the underdose LMWH group, the incidence of major adverse vascular events was similar to that of the group receiving the recommended dose $(2.6 \%$ vs. $2.9 \%$ ). Previous data have demonstrated that patients with low anti-Xa activity increased 30-day mortality [19]. This may be due to the fact that the underdose of LMWH in our study doesn't indicate low anti-Xa activity as LMWH has linear pharmacokinetics but high betweensubject variability $[20,21]$. On the other hand, clinical outcomes are also influenced by patients' characteristics and not only the dosage of LMWH. In the above mentioned study, patients with sub-therapeutic anti-Xa levels were significantly older, and had more impaired renal function and inferior heart function compared with others [19]. However, in our study, patients that received underdoses of LMWH had better baseline characteristics (younger and better renal function) than the recommended and excess dose groups; this may be the primary reason that the underdosing of LMWH was not found to be a risk factor for embolism in our study.

Since there were no severe RI patients receiving underdoses of LMWH, a fixed and weight-independent dosage may be not suitable for severe RI patients. LMWHs are not recommended for use in patients with severe RI due to the risk of accumulation may lead to major bleeding $[11,22,23]$. According to the results of the ExTRACT-TIMI 25 trial [11], a dose of $1 \mathrm{mg} / \mathrm{kg}$ of enoxaparin every $24 \mathrm{~h}$ was recommended for patients with an estimated creatinine clearance $<30 \mathrm{ml} / \mathrm{min}$. However, in our study, major adverse vascular events occurred more often in severe RI patients than in patients with creatine clearance $\geq 30 \mathrm{ml} / \mathrm{min}$ ( $30 \%$ vs. $1.3 \%, P<0.001$ ), although $57.1 \%(4 / 7)$ of severe RI patients receiving excess doses 
of LMWH. After multivariable analysis, we found that severe RI is the only predictor of major adverse vascular events. In elderly patients ( $\geq 75$ years), STEMI patients, excess doses of LMWH were not independent predictors of major adverse vascular events. Results from the current study are consistent with those from previous studies in which patients with RI have a higher risk for thromboembolic complications [24-26], and support the recommendation for dose adjustments based on anti-Xa activity and not calculated based on a simple dose scheme for LMWH used in RI patients [27]. Our results indicate that using LMWH at a fixed, lower dose in patients without severe RI may be safe and effective.

Nevertheless, there are some limitations to this study. First, our findings are based on the results of a onecenter, retrospective study, complementing the prospect and lack of follow-up. Second, unlike randomized trials that have more restrictive inclusion criteria, it must be noted that the patient characteristics in this study were not as well-controlled. Third, due to a lack of anti-Xa assay in our hospital, we could not measure anti-Xa activity in RI patients. Finally, small sample size is a potential limiting factor in this study as well.

\section{Conclusions}

In summary, the current study demonstrated that underdose of LMWH is commonly used in cardiovascular inpatients. Using $\mathrm{LMWH}$ in a fixed, lower dose for treatment purposes in patients without severe RI was not associated with a high risk of adverse vascular events in our study. Larger studies with extended follow-ups are required to fully assess the long-term consequences of LMWH underdosing.

\section{Competing interests}

The authors declare that there are no conflicts of interest regarding this study to be disclosed.

\section{Authors' contributions}

$\mathrm{HX}, \mathrm{HC}$ and ZQ carried out the medical records database search, statistical analysis, and drafted the manuscript. GX, XY, and HD participated in the design and coordination of the study and helped to draft the manuscript. All authors read and approved the final manuscript.

\section{Acknowledgments}

This project was supported by the grant from the National Natural Science Foundation of China (81173040), and the Foundation from the Health Bureau of Zhejiang Province (2011KYA065, 2012RCA027).

\section{Author details}

'Department of Pharmacy, Second Affiliated Hospital, Zhejiang University School of Medicine, Hangzhou 310009, China. ${ }^{2}$ Department of Cardiovascular Medicine, First Affiliated Hospital, Zhejiang Chinese Medical University, Hangzhou 310006, China. ${ }^{3}$ Department of Cardiovascular Medicine, Second Affiliated Hospital, Zhejiang University School of Medicine, Hangzhou 310009, China.

Received: 20 July 2012 Accepted: 28 November 2012

Published: 5 December 2012

\section{References}

1. Michaels AD, Spinler SA, Leeper B, Ohman EM, Alexander KP, Newby LK, Ay $\mathrm{H}$, Gibler WB: Medication errors in acute cardiovascular and stroke patients: a scientific statement from the American Heart Association. Circulation 2010, 121(14):1664-1682.

2. Hirsh J, Warkentin TE, Shaughnessy SG, Anand SS, Halperin JL, Raschke R, Granger C, Ohman EM, Dalen JE: Heparin and low-molecular-weight heparin: mechanisms of action, pharmacokinetics, dosing, monitoring, efficacy, and safety. Chest 2001, 119(1 Suppl):64S-94S.

3. Erkens PM, Prins MH: Fixed dose subcutaneous low molecular weight heparins versus adjusted dose unfractionated heparin for venous thromboembolism. Cochrane Database Syst Rev 2010, (9):CD001100.

4. Magee KD, Sevcik W, Moher D, Rowe BH: Low molecular weight heparins versus unfractionated heparin for acute coronary syndromes. Cochrane Database Syst Rev 2003, (1):CD002132.

5. Font MA, Krupinski J, Arboix A: Antithrombotic medication for cardioembolic stroke prevention. Stroke Res Treat 2011, 2011:607852.

6. Hirsh J, Raschke R: Heparin and low-molecular-weight heparin: the seventh ACCP conference on antithrombotic and thrombolytic therapy. Chest 2004, 126(3 Suppl):188S-203S.

7. Warkentin TE, Levine MN, Hirsh J, Horsewood P, Roberts RS, Gent M, Kelton $J \mathrm{G}$ : Heparin-induced thrombocytopenia in patients treated with low-molecular-weight heparin or unfractionated heparin. N Engl I Med 1995, 332(20):1330-1335.

8. Schulman S, Beyth RJ, Kearon C, Levine MN: Hemorrhagic complications of anticoagulant and thrombolytic treatment: american college of chest physicians evidence-based clinical practice guidelines (8th edition). Chest 2008, 133(6 Suppl):257S-298S.

9. Cohen M, Demers C, Gurfinkel EP, Turpie AG, Fromell GJ, Goodman S, Langer A, Califf RM, Fox KA, Premmereur J, et al: A comparison of low-molecular-weight heparin with unfractionated heparin for unstable coronary artery disease efficacy and safety of subcutaneous enoxaparin in Non-Q-wave coronary events study group. N Engl J Med 1997, 337(7):447-452.

10. The FRAX.IS. Study Group: Comparison of two treatment durations (6 days and 14 days) of a low molecular weight heparin with a 6-day treatment of unfractionated heparin in the initial management of unstable angina or non-Q wave myocardial infarction: FRAX.I.S. (FRAxiparine in Ischaemic Syndrome). Eur Heart J 1999, 20(21):1553-1562.

11. Klein W, Buchwald A, Hillis SE, Monrad S, Sanz G, Turpie AG, van der Meer J, Olaisson E, Undeland S, Ludwig K: Comparison of low-molecular-weight heparin with unfractionated heparin acutely and with placebo for 6 weeks in the management of unstable coronary artery disease. Fragmin in unstable coronary artery disease study (FRIC). Circulation 1997, 96(1):61-68.

12. Bauman ME, Black KL, Bauman ML, Belletrutti M, Bajzar L, Massicotte MP: Novel uses of insulin syringes to reduce dosing errors: a retrospective chart review of enoxaparin whole milligram dosing. Thromb Res 2009, 123(6):845-847.

13. Macie C, Forbes L, Foster GA, Douketis JD: Dosing practices and risk factors for bleeding in patients receiving enoxaparin for the treatment of an acute coronary syndrome. Chest 2004, 125(5):1616-1621.

14. Fox KA, Antman EM, Montalescot G, Agewall S, SomaRaju B, Verheugt FW, Lopez-Sendon J, Hod H, Murphy SA, Braunwald E: The impact of renal dysfunction on outcomes in the ExTRACT-TIMI 25 trial. J Am Coll Cardiol 2007, 49(23):2249-2255.

15. Alexander KP, Chen AY, Roe MT, Newby LK, Gibson CM, Allen-LaPointe NM, Pollack C, Gibler WB, Ohman EM, Peterson ED: Excess dosing of antiplatelet and antithrombin agents in the treatment of non-STsegment elevation acute coronary syndromes. JAMA 2005, 294(24):3108-3116

16. Camm AJ, Kirchhof P, Lip GY, Schotten U, Savelieva I, Ernst S, Van Gelder IC, Al-Attar N, Hindricks G, Prendergast B, et al: Guidelines for the management of atrial fibrillation: the task force for the management of atrial fibrillation of the European Society of Cardiology (ESC). Eur Heart $J$ 2010, 31(19):2369-2429.

17. Lin BW, Yoshida D, Quinn J, Strehlow M: A better way to estimate adult patients' weights. Am J Emerg Med 2009, 27(9):1060-1064.

18. Anglemyer BL, Hernandez C, Brice JH, Zou B: The accuracy of visual estimation of body weight in the ED. Am J Emerg Med 2004, 22(7):526-529. 
19. Montalescot G, Collet JP, Tanguy ML, Ankri A, Payot L, Dumaine R, Choussat R, Beygui F, Gallois V, Thomas D: Anti-Xa activity relates to survival and efficacy in unselected acute coronary syndrome patients treated with enoxaparin. Circulation 2004, 110(4):392-398.

20. Al-Sallami HS, Barras MA, Green B, Duffull SB: Routine plasma anti-Xa monitoring is required for low-molecular-weight heparins. Clin Pharmacokinet 2010, 49(9):567-571.

21. Singer JP, Huang MY, Hui C, Blanc PD, Boettger RF, Golden J, Watkins K, Hoopes C, Leard LE: Supratherapeutic anticoagulation from low-molecular-weight heparin in lung transplant recipients. J Heart Lung Transplant 2010, 29(9):1009-1013.

22. Bazinet A, Almanric K, Brunet C, Turcotte I, Martineau J, Caron S, Blais N, Lalonde $L$ : Dosage of enoxaparin among obese and renal impairment patients. Thromb Res 2005, 116(1):41-50.

23. Schmid P, Fischer AG, Wuillemin WA: Low-molecular-weight heparin in patients with renal insufficiency. Swiss Med Wkly 2009, 139(31-32):438-452.

24. Frydman A: Low-molecular-weight heparins: an overview of their pharmacodynamics, pharmacokinetics and metabolism in humans. Haemostasis 1996, 26(Suppl 2):24-38.

25. Jacobs DR Jr, Kroenke C, Crow R, Deshpande M, Gu DF, Gatewood L, Blackburn H: PREDICT: A simple risk score for clinical severity and long-term prognosis after hospitalization for acute myocardial infarction or unstable angina: the Minnesota heart survey. Circulation 1999, 100(6):599-607.

26. Collet JP, Montalescot G, Fine E, Golmard JL, Dalby M, Choussat R, Ankri A, Dumaine R, Lesty C, Vignolles $N$, et al: Enoxaparin in unstable angina patients who would have been excluded from randomized pivotal trials. J Am Coll Cardiol 2003, 41(1):8-14.

27. Schmid P, Brodmann D, Odermatt Y, Fischer AG, Wuillemin WA: Study of bioaccumulation of dalteparin at a therapeutic dose in patients with renal insufficiency. J Thromb Haemost 2009, 7(10):1629-1632.

doi:10.1186/1471-2261-12-118

Cite this article as: Xu et al:: Dosing practice of low molecular weight heparins and its efficacy and safety in cardiovascular inpatients: a retrospective study in a Chinese teaching hospital. BMC Cardiovascular Disorders 2012 12:118.

\section{Submit your next manuscript to BioMed Central and take full advantage of:}

- Convenient online submission

- Thorough peer review

- No space constraints or color figure charges

- Immediate publication on acceptance

- Inclusion in PubMed, CAS, Scopus and Google Scholar

- Research which is freely available for redistribution 